NATIONAL LABORATORY

\title{
Effects of Gain Changes on RPM Performance
}

\section{March 2012}

\section{Prepared by}

Angela Lousteau

Rob York

Jake Livesay

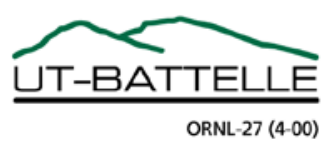




\section{DOCUMENT AVAILABILITY}

Reports produced after January 1, 1996, are generally available free via the U.S. Department of Energy (DOE) Information Bridge.

Web site http://www.osti.gov/bridge

Reports produced before January 1, 1996, may be purchased by members of the public from the following source.

National Technical Information Service

5285 Port Royal Road

Springfield, VA 22161

Telephone 703-605-6000 (1-800-553-6847)

TDD 703-487-4639

Fax 703-605-6900

E-mail info@ntis.gov

Web site http://www.ntis.gov/support/ordernowabout.htm

Reports are available to DOE employees, DOE contractors, Energy Technology Data Exchange (ETDE) representatives, and International Nuclear Information System (INIS) representatives from the following source.

Office of Scientific and Technical Information

P.O. Box 62

Oak Ridge, TN 37831

Telephone 865-576-8401

Fax 865-576-5728

E-mail reports@osti.gov

Web site http://www.osti.gov/contact.html

This report was prepared as an account of work sponsored by an agency of the United States Government. Neither the United States Government nor any agency thereof, nor any of their employees, makes any warranty, express or implied, or assumes any legal liability or responsibility for the accuracy, completeness, or usefulness of any information, apparatus, product, or process disclosed, or represents that its use would not infringe privately owned rights. Reference herein to any specific commercial product, process, or service by trade name, trademark, manufacturer, or otherwise, does not necessarily constitute or imply its endorsement, recommendation, or favoring by the United States Government or any agency thereof. The views and opinions of authors expressed herein do not necessarily state or reflect those of the United States Government or any agency thereof. 
ORNL/TM-2012/58

Global Nuclear Security Technology Division

\title{
Effects of Gain Changes on RPM Performance
}

\author{
Angela Lousteau \\ Rob York \\ Jake Livesay
}

Date Published: March 2012

Prepared by

OAK RIDGE NATIONAL LABORATORY

Oak Ridge, Tennessee 37831-6283

managed by

UT-BATTELLE, LLC

for the

US DEPARTMENT OF ENERGY

under Contract No. DE-AC05-00OR22725 



\section{CONTENTS}

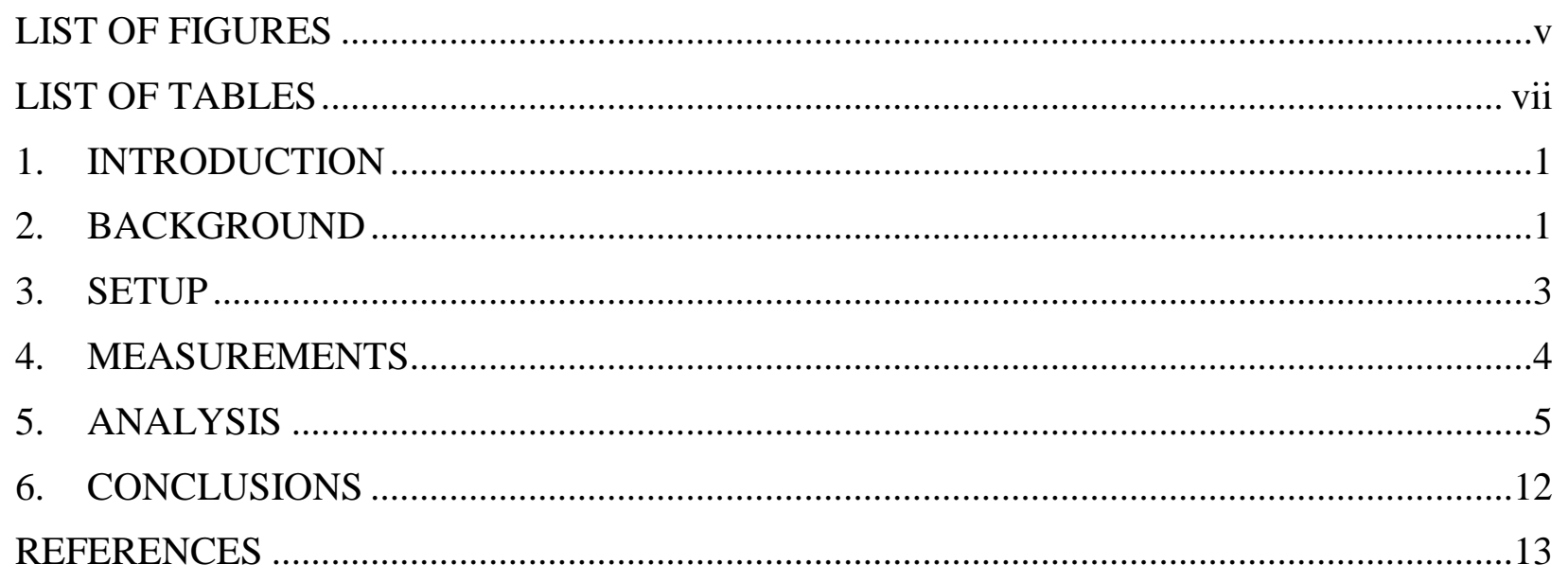





\section{LIST OF FIGURES}

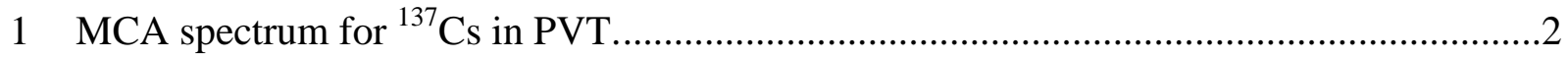

2 Total net count rate, S, vs ${ }^{137}$ Cs Compton Maximum position. .........................................6

3 Total background count rate, $\mathrm{B}$, vs ${ }^{137} \mathrm{Cs}$ Compton Maximum position.............................

4 Normalized figure of merit for HEU measurements with fixed discriminators..................8

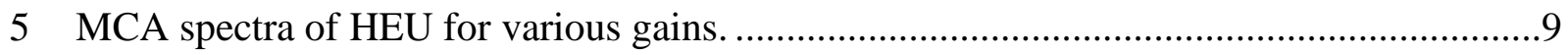

6 Normalized figure of merit for HEU measurements with

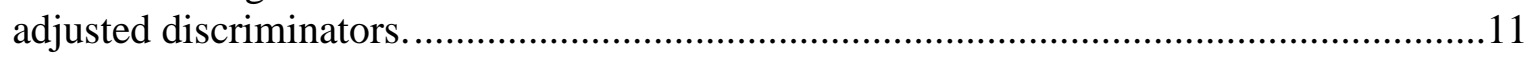

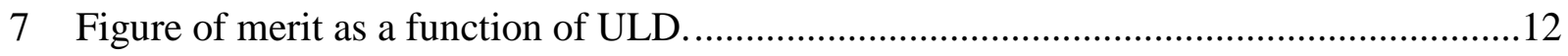





\section{LIST OF TABLES}

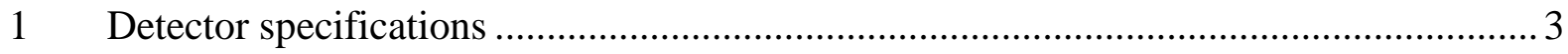

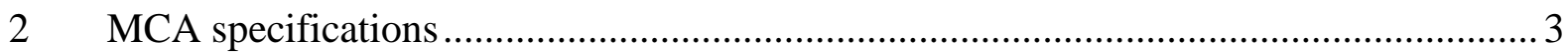

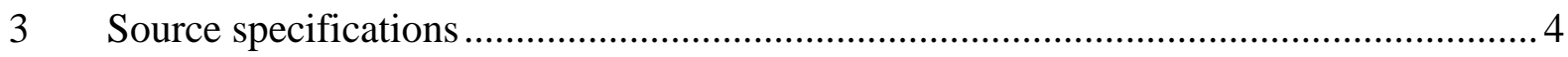

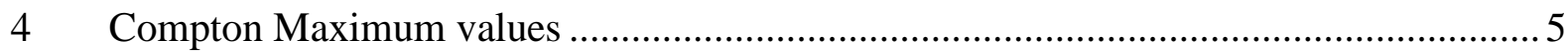

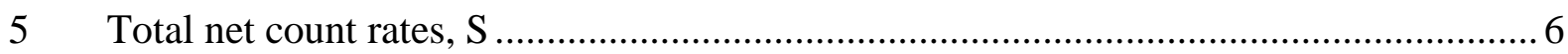

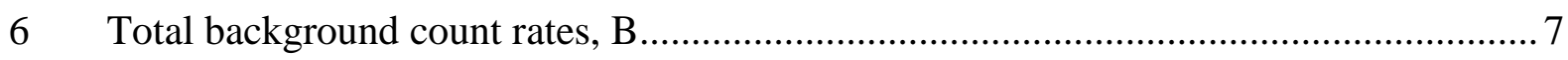

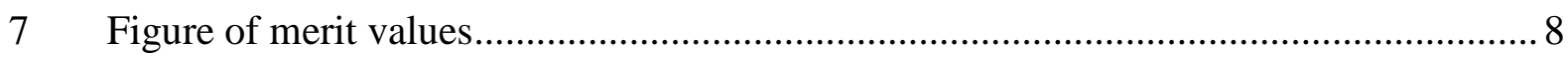

8 Calculated position of the Upper Edge................................................................. 10 



\section{INTRODUCTION}

The mission of the U.S. Department of Energy/National Nuclear Security Administration's (DOE/NNSA's) Office of the Second Line of Defense (SLD) is to strengthen the capability of foreign governments to deter, detect, and interdict the illicit trafficking of special nuclear and other radioactive materials across international borders and through the global maritime shipping system. The goal of this mission is to reduce the probability of these materials being fashioned into a weapon of mass destruction or radiological dispersal device that could be used against the United States or its international partners. This goal is achieved primarily through the installation and operation of radiation detection equipment at border crossings, airports, seaports, and other strategic locations around the world. In order to effectively detect the movement of radioactive material, the response of these radiation detectors to various materials in various configurations must be well characterized. Oak Ridge National Laboratory (ORNL) investigated two aspects of Radiation Portal Monitor (RPM) settings, based on a preliminary investigation done by the Los Alamos National Laboratory (LANL): source-to-detector distance effect on amplifier gain and optimized discriminator settings. This report discusses this investigation.

\section{BACKGROUND}

Special nuclear and other radioactive materials emit various radiation particles. Specifically, these materials emit gamma rays and/or neutrons that can be detected to determine the presence of radioactive material and, in some cases, used to identify the specific type of material. Polyvinyl toluene (PVT) and polystyrene (PS) are two types of plastic scintillator detectors used to detect gamma radiation in RPMs used by SLD.

Scintillation detectors scintillate, or emit light in the form of photons, when excited by ionizing radiation. Gamma rays are a type of ionizing radiation emitted by radioactive isotopes, the materials of interest. When a gamma ray from a radioactive isotope hits the scintillation material (in this case plastic), it excites the atoms by knocking electrons into different orbitals. As those atoms de-excite, and the electrons fall back into the correct orbitals, light is emitted. This light is then converted into a voltage pulse whose magnitude is proportional to the amount of energy deposited by the incident gamma ray that hit the scintillator. The detection of this visible light, therefore, is indicative of the presence of ionizing radiation.

The conversion of light into a voltage pulse is performed through a series of steps. The light in the scintillator is reflected into a photomultiplier tube (PMT) whose surface is coated with a photo-emitter with less work potential, known as a photocathode. When a scintillation photon strikes the photocathode, an electron is emitted. The electron is then accelerated towards an electrode, specifically called a dynode, with an increased positive potential. When the electron hits the dynode, additional secondary electrons are released, which accelerate towards a second dynode. This prolific process, known as avalanching, continues until the electrons hit the last 
dynode in the PMT and there are enough to send a voltage pulse across external resistors. This pulse is amplified and counted by the detector.

Because the pulse height is proportional to the amount of energy deposited by the incident gamma ray, it is possible to separate and collect each pulse, by pulse height, producing an energy spectrum. Although it would be ideal to capture the full energy photopeak, thereby allowing identification of the emitting material, it is not feasible using plastic scintillators. Instead, the part of the energy spectrum seen is referred to as the Compton continuum, the lower energy region caused by photon scattering, and partial energy deposition, in the scintillator.

An example of the measured spectrum, from a Multi-Channel Analyzer (MCA), for a ${ }^{137} \mathrm{Cs}$ source is shown in Fig. 1. The peak near channel 124 is referred to as the Compton maximum. The alignment, or calibration, of an RPM is performed by placing this Compton maximum, specifically for ${ }^{137} \mathrm{Cs}$, in a particular channel specified by the manufacturer. This alignment ensures the correct gain settings for the monitor and encourages optimal detector response.

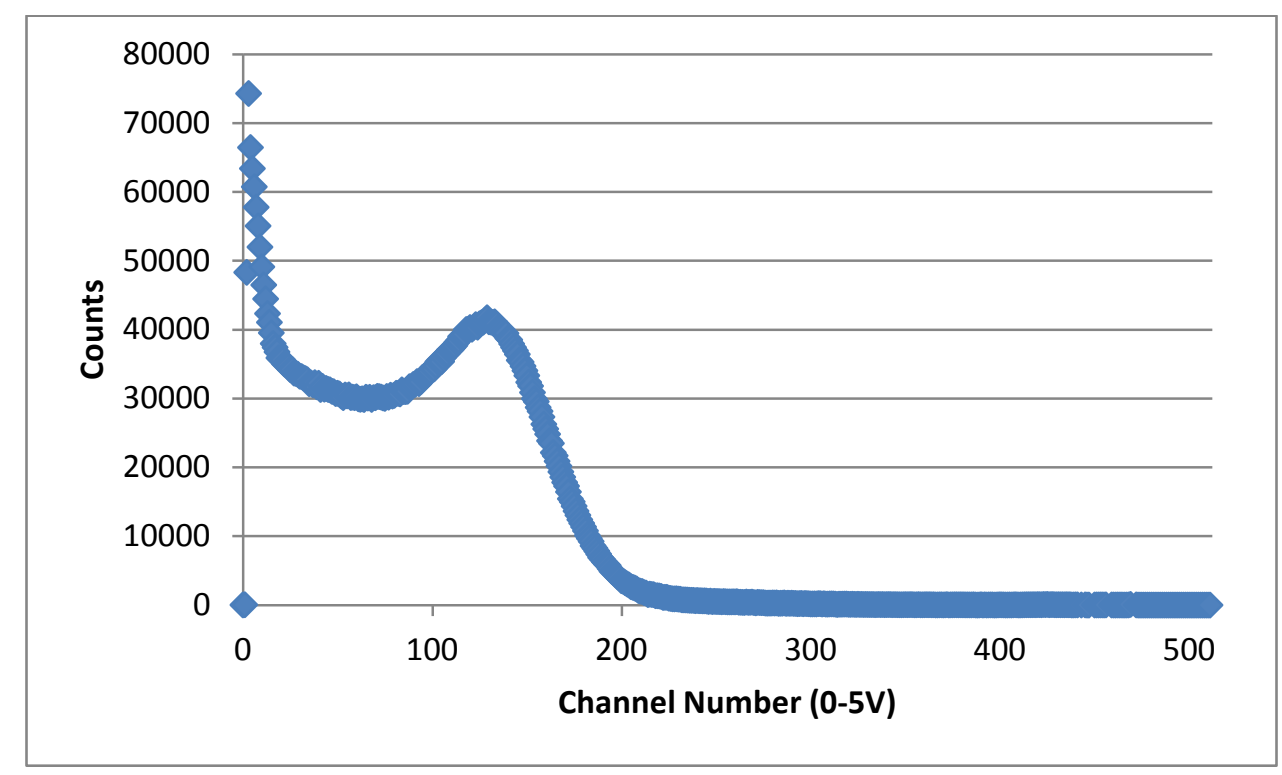

Fig. 1. MCA spectrum for ${ }^{137}$ Cs in PVT.

The alignment process for monitors in the SLD program typically involves the use of an oscilloscope to set the Compton maximum to $0.75 \pm 0.05 \mathrm{~V}$ in the first stage and $2.0 \pm 0.1 \mathrm{~V}$ in the second stage. Recently, MCAs have been used to record the energy spectrum for various measurements to better understand the effects of gain changes on detector response. The alignment procedure using an MCA, initially authored by ORNL, is referenced at the end of this document. 
MCA spectra were recorded for a highly enriched uranium (HEU) source at 2 meters from the detector, at 1 meter from the detector, and on contact with the detector. The gain was then shifted in small increments, and the measurements were repeated. Background spectra were collected for each gain shift as well as spectra for a ${ }^{137}$ Cs source on contact with the detector. The gain shifts will be identified throughout this document by the channel position of the Compton Maximum in each spectrum. The spectra were then analyzed to better understand the relationship between the source-detector spacing and gain change. The measurements and results are the focus of this paper.

A ${ }^{137}$ Cs spectrum was collected using the MCA. The Compton maximum was recorded and the spectrum was saved. An HEU source was then place $1.1 \mathrm{~m}$ away from the center of the plastic slab. The energy spectrum was then collected and saved. The counts were integrated based on the discriminator settings to get a total count rate. Background was subtracted to get the net counts in the appropriate window. The net count rate was divided by the square root of the background to get the figure of merit. This figure of merit was then plotted as a function of the Compton maximum channel number. This was then repeated for the source directly against the detector.

\section{SETUP}

A PVT plastic scintillator from an SLD RPM was used for this test. The specifications for this detector are listed in Table 1 . The detector setup included the standard side and back lead shielding. The center of the detector was $135 \mathrm{~cm}$ above the floor. The spectra were collected and recorded using an Amptek Pocket MCA. The specifications for the MCA are listed in Table 2.

Table 1. Detector specifications

\begin{tabular}{|l|l|}
\hline Manufacturer & TSA \\
\hline Model number & DA-630 \\
\hline Scintillator serial number & 314739 \\
\hline PMT serial number & 5534 \\
\hline Dimensions (in.) & $6 \times 30$ \\
\hline
\end{tabular}

Table 2. MCA specifications

\begin{tabular}{|l|l|}
\hline Manufacturer & Amptek \\
\hline Model number & $8000 \mathrm{~A}$ \\
\hline Serial number & 003841 \\
\hline Number of channels & 512 \\
\hline Voltage setting & $5 \mathrm{~V}$ \\
\hline
\end{tabular}


Both ${ }^{137} \mathrm{Cs}$ and HEU were used for the following measurements. Source specifications are given in Table 3.

Table 3. Source specifications

\begin{tabular}{|l|l|}
\hline \multicolumn{2}{|c|}{${ }^{137}$ Cs } \\
\hline Identification & 5614 \\
\hline Activity & $4.99 \mu \mathrm{Ci}$ \\
\hline Date & $07-20-2005$ \\
\hline \multicolumn{2}{|c|}{ HEU } \\
\hline Identification & NBL CRM U930 \\
\hline Form & Uranium or alloy metal disk \\
\hline Enrichment & $93.162 \mathrm{w} / \mathrm{o}$ \\
\hline Uranium mass & $11.7 \mathrm{~g}$ \\
\hline Diameter & $3.37 \mathrm{~cm}$ \\
\hline
\end{tabular}

\section{MEASUREMENTS}

To begin the measurements, a ${ }^{137} \mathrm{Cs}$ source was placed against the center of the detector on the yellow dot provided by the manufacturer. Test probes attached to the second-stage test pin (TP6) and ground (TP32) were input into the MCA receptacle. A 600 second spectrum was recorded, and the Compton Maximum was noted. The source was removed, and a 600 second background spectrum was recorded.

A HEU source was then placed on contact at the center of the scintillator. A 100 second spectrum was collected. The source was then removed and placed at 1 meter away from the face of the scintillator. A 600 second spectrum was recorded. The source was again removed and placed at 2 meters away from the face of the detector. A longer 900 second spectrum was collected for this scenario to increase counting statistics.

The ${ }^{137}$ Cs was then placed against the center of the detector on the yellow dot provided by the manufacturer. The gain was adjusted by turning the potentiometer. The measurements were repeated such that there were five spectra recorded for each gain setting. Table 4 lists the Compton Maximums for each set of measurements.

The HEU measurements on contact, at 1 meter, and at 2 meters were then repeated for each new Compton Maximum position. 
Table 4. Compton Maximum values

\begin{tabular}{|c|}
\hline $\begin{array}{c}\text { Compton Maximum Positions } \\
\text { (channel number) }\end{array}$ \\
\hline 116 \\
\hline 124 \\
\hline 147 \\
\hline 199 \\
\hline 253 \\
\hline 278 \\
\hline 327 \\
\hline 344 \\
\hline 356 \\
\hline 376 \\
\hline
\end{tabular}

\section{ANALYSIS}

After the spectra were collected, the raw data, namely, the counts per channel, were exported to an excel spreadsheet. The background was then subtracted from the HEU measurements, yielding the net counts per channel for each measurement distance at the various gains.

The upper and lower level discriminators are set to 0.455 and $0.069 \mathrm{~V}$, respectively, and thus are not affected by changes in the gain. For example, the gain may drift over time shifting the spectra; however, the discriminators are fixed at 0.455 and $0.069 \mathrm{~V}$, unless the changes are keyed into the single channel analyzer SCA controller. Based on 512 channels and $5 \mathrm{~V}$, these discriminators correlate to channels 46 and 8, respectively. This is under the assumption that the MCA is linear.

By summing the net counts in the channels between 8 and 46, inclusive, a total net count was calculated. By dividing this number by the count time, a total net count rate, S, was determined. The total net count rate, S, was calculated for each source position at each gain setting. These values are listed in Table 5. 
Table 5. Total net count rates, $\mathrm{S}$

\begin{tabular}{|c|c|c|c|}
\hline \multirow{2}{*}{$\begin{array}{c}\text { Gain (Compton Maximum } \\
\text { channel number) }\end{array}$} & \multicolumn{3}{|c|}{ Total net count rate, S, for HEU (cps) } \\
\cline { 2 - 4 } & On contact & At 1 meter & At 2 meters \\
\hline 116 & 26863.4 & 660.2 & 183.7 \\
\hline 124 & 28172.0 & 698.5 & 198.0 \\
\hline 147 & 31359.9 & 787.7 & 225.8 \\
\hline 199 & 32172.0 & 828.3 & 233.5 \\
\hline 253 & 33364.2 & 897.7 & 265.7 \\
\hline 278 & 32604.4 & 894.1 & 264.6 \\
\hline 327 & 32359.6 & 902.1 & 265.5 \\
\hline 344 & 32259.6 & 891.7 & 272.0 \\
\hline 356 & 32253.1 & 891.2 & 264.1 \\
\hline 376 & 31146.2 & 870.2 & 271.9 \\
\hline
\end{tabular}

Figure 2 shows the total net count rate, $\mathrm{S}$, for the HEU source on contact, at 1 meter, and at 2 meters away from the face of the detector. Note that the primary axis (left-hand side) correlates to the "on contact" data, while the secondary axis (right-hand side) correlates to the 1 and 2 meter data.

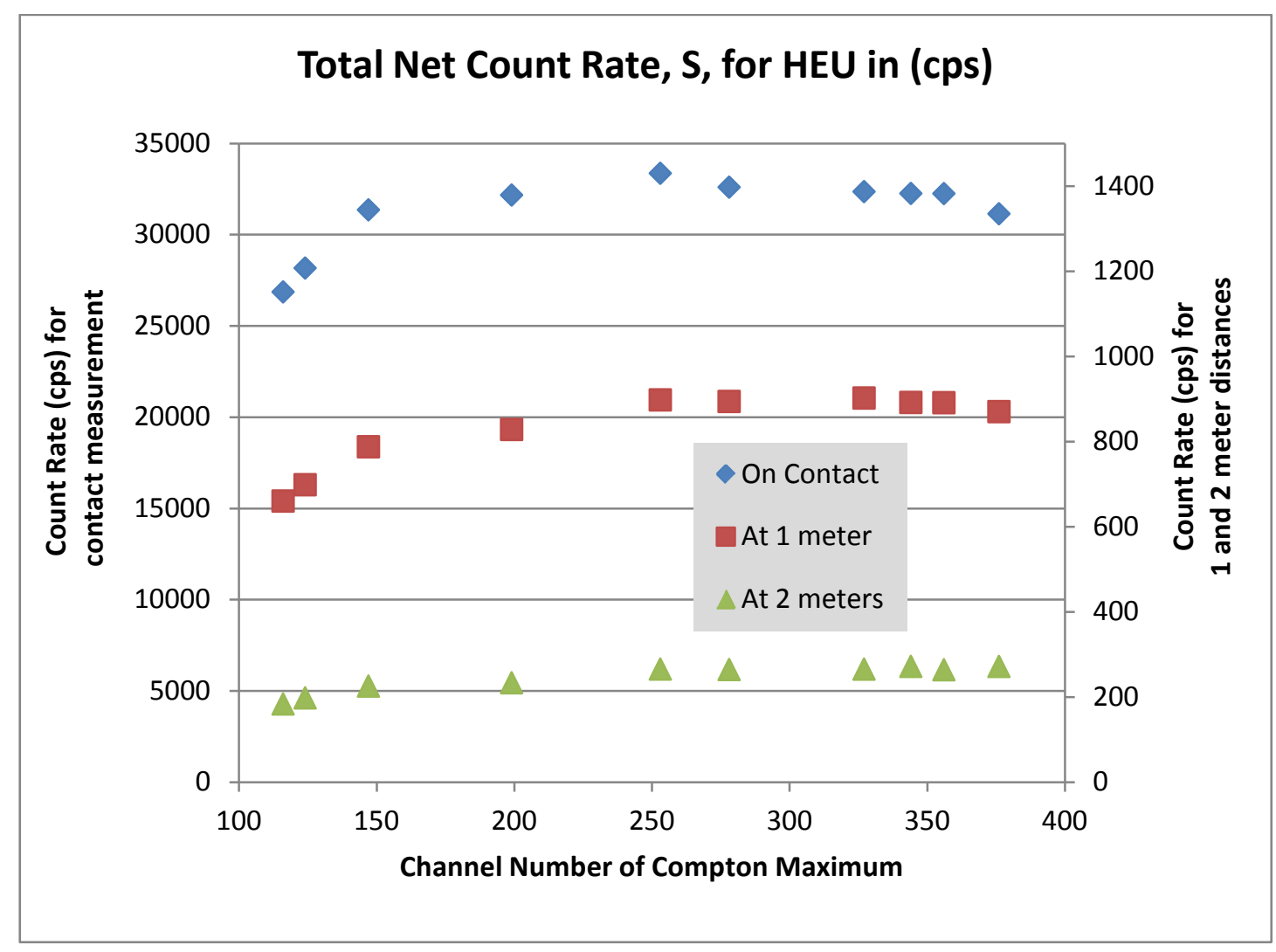

Fig. 2. Total net count rate, S, vs ${ }^{137}$ Cs Compton Maximum position. 
Additionally, the total background count rate, $\mathrm{B}$, and the square root of $\mathrm{B}$, were computed for each gain setting. These values are given Table 6 .

Table 6. Total background count rates, $\mathrm{B}$

\begin{tabular}{|c|c|c|}
\hline $\begin{array}{c}\text { Gain (Compton Maximum } \\
\text { channel number) }\end{array}$ & $\begin{array}{c}\text { Total background count } \\
\text { rate, B (cps) }\end{array}$ & $\sqrt{ }_{\mathbf{B}}$ \\
\hline 116 & 280.8 & 16.8 \\
\hline 124 & 283.5 & 16.8 \\
\hline 147 & 295.8 & 17.2 \\
\hline 199 & 287.2 & 16.9 \\
\hline 253 & 304.1 & 17.4 \\
\hline 278 & 307.8 & 17.5 \\
\hline 327 & 366.0 & 19.1 \\
\hline 344 & 431.3 & 20.8 \\
\hline 356 & 442.5 & 21.0 \\
\hline 376 & 451.5 & 21.2 \\
\hline
\end{tabular}

Figure 3 shows the background data plotted as a function of the position of the ${ }^{137}$ Cs Compton Maximum. The rise in background seen in the plot is a result of noise being "pushed" into the region of interest (above the lower level discriminator (LLD)).

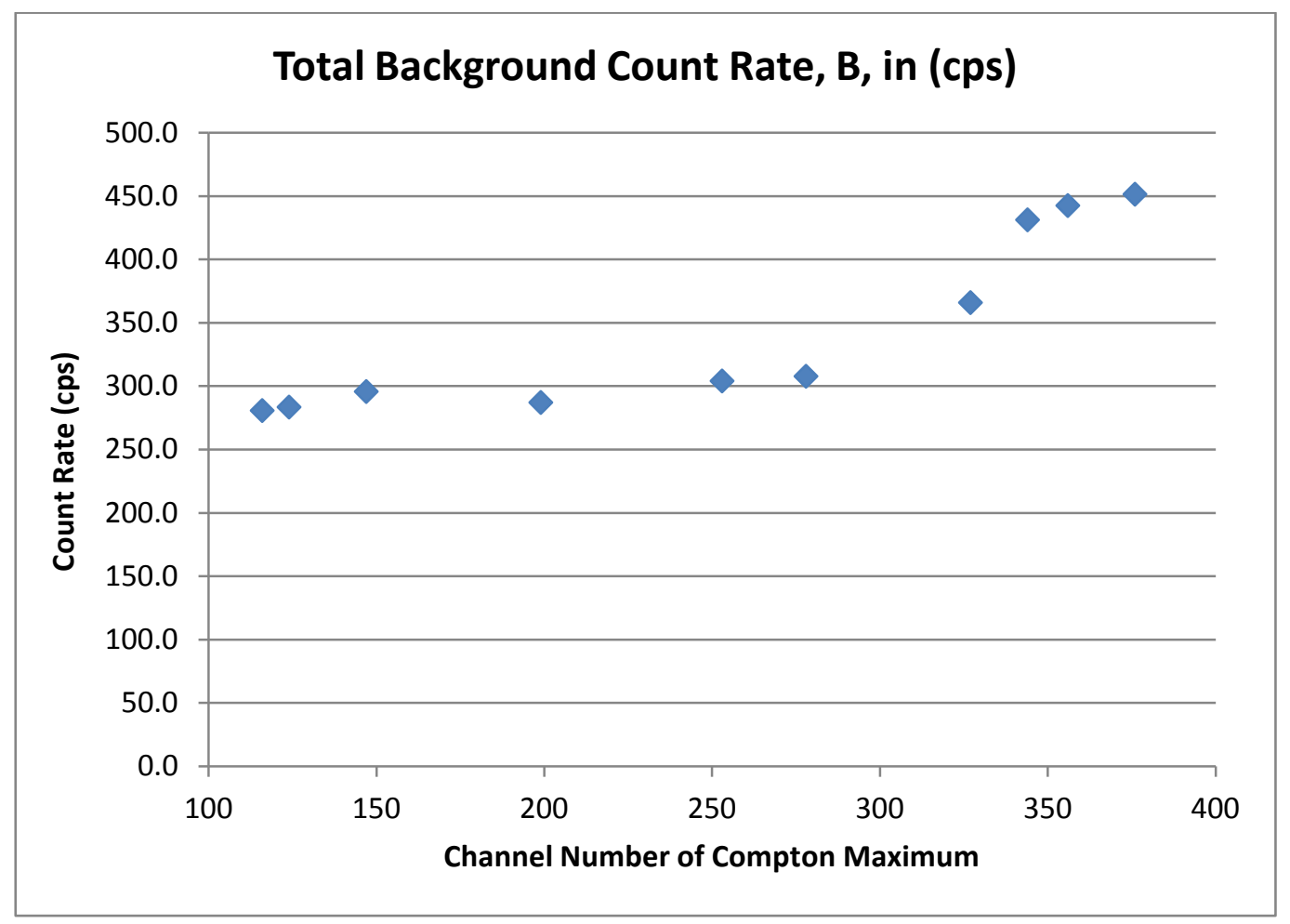

Fig. 3. Total background count rate, B, vs ${ }^{137}$ Cs Compton Maximum position. 
A common figure of merit, $\mathrm{S} / \sqrt{\mathrm{B}}$, was then determined. The normalized values are given in Table 7 for each measurement scenario. These values are also plotted in Fig. 4. Figure 4 shows the figure of merit, $\mathrm{S} / \sqrt{\mathrm{B}}$, for the $\mathrm{HEU}$ source on contact, at 1 meter, and at 2 meters away from the face of the detector.

Table 7. Figure of merit values

\begin{tabular}{|c|c|c|c|}
\hline \multirow{2}{*}{$\begin{array}{c}\text { Gain (Compton Maximum } \\
\text { channel number) }\end{array}$} & \multicolumn{3}{|c|}{ Figure of Merit, $\mathbf{S} \sqrt{\mathbf{B}, \text { for } \mathbf{H E U}}$} \\
\cline { 2 - 4 } & On contact & At 1 meter & At 2 meters \\
\hline 116 & 0.88 & 0.86 & 0.84 \\
\hline 124 & 0.92 & 0.91 & 0.90 \\
\hline 147 & 1.00 & 1.00 & 1.00 \\
\hline 199 & 1.04 & 1.07 & 1.05 \\
\hline 253 & 1.05 & 1.12 & 1.16 \\
\hline 278 & 1.02 & 1.11 & 1.15 \\
\hline 327 & 0.93 & 1.03 & 1.06 \\
\hline 344 & 0.85 & 0.94 & 1.00 \\
\hline 356 & 0.84 & 0.92 & 0.96 \\
\hline 376 & 0.80 & 0.89 & 0.97 \\
\hline
\end{tabular}

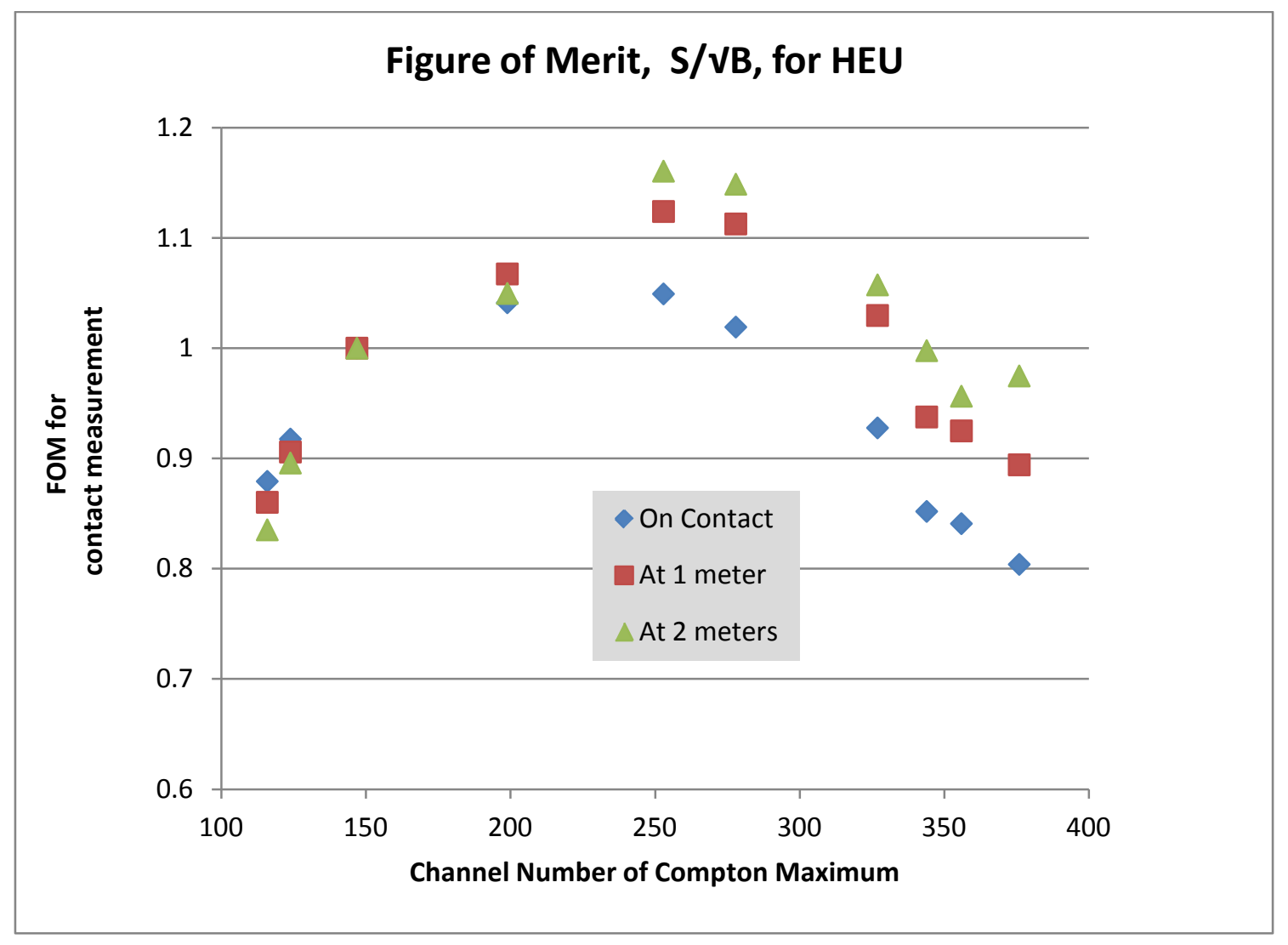

Fig. 4. Normalized figure of merit for HEU measurements with fixed discriminators. 
The response for all three measurement distances is as expected. As the gain increases in the beginning, the figure of merit increases, because more of the HEU signal is being "pushed” into the region of interest above the LLD, without "pushing" the upper end of the signal beyond the upper level discriminator (ULD). However, it is also apparent that at some point the figure of merit begins decreasing. This is due to the fact that the HEU signal is now being pushed above the ULD. These effects can be seen in Fig. 5, which shows the MCA spectra for various gains.

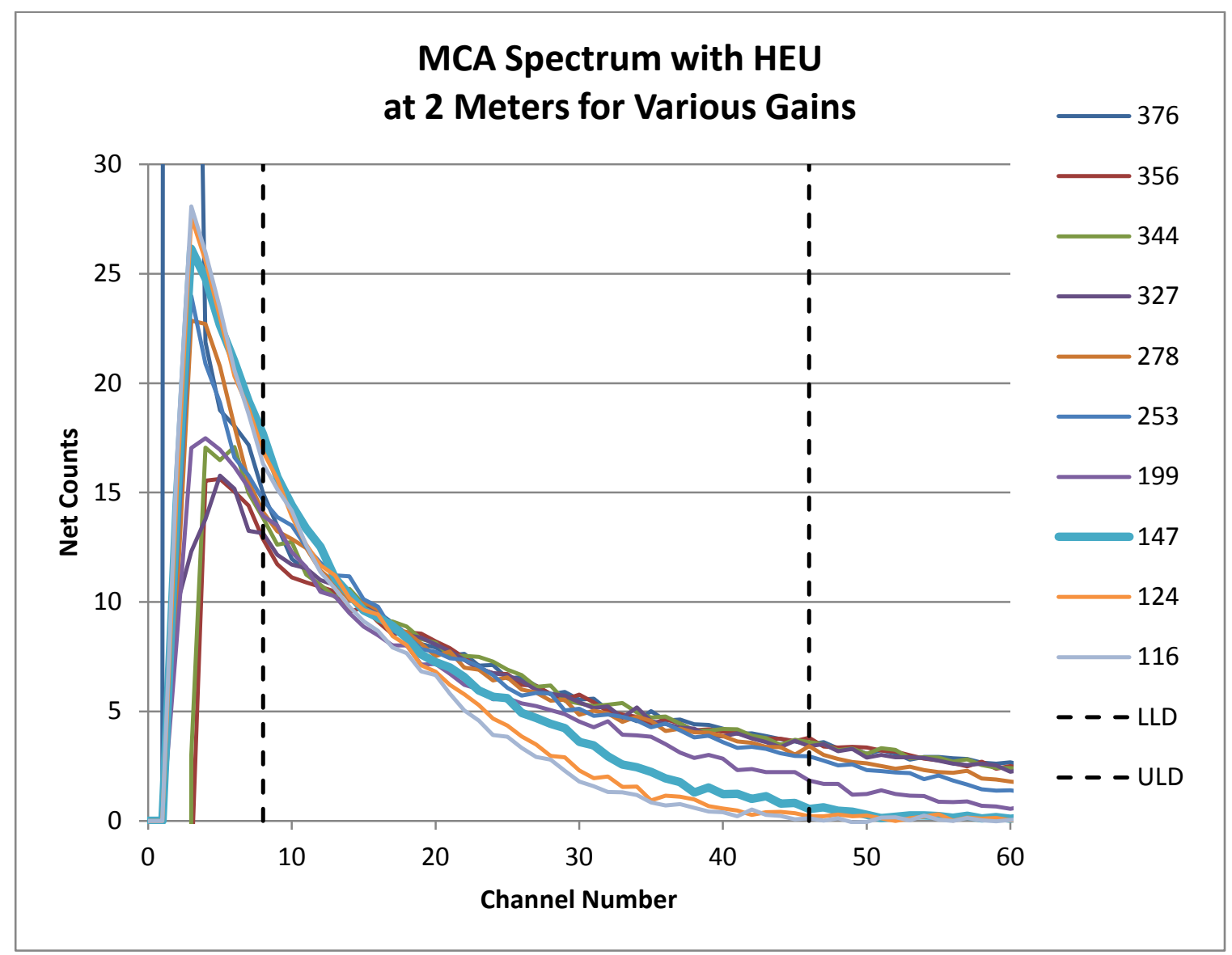

Figure 5. MCA spectra of HEU for various gains.

From Fig. 4, it is obvious that the value of $S / \sqrt{ } B$ changes with changing gain; however, this is assuming the discriminator settings are not adjusted to account for the new position of the Compton continuum. If the discriminator settings were adjusting accordingly, we expect the figure of merit curve to be constant for a wide range of gains. In order to verify this, a new set of discriminators was determined and applied to the previously recorded measurements. The results are discussed below.

When originally aligning the monitor, an oscilloscope was used to set the upper edge of the brightest band (for simplicity, this will be referred to as the Upper Edge) to $2 \mathrm{~V}$. In the MCA, 2 V corresponds to channel 204 (based on 5 V, 512 channels, and assuming the MCA is linear). 
After setting the Upper Edge to $2 \mathrm{~V}$, an MCA spectrum was collected. The position of the Compton maximum was noted at channel 147. The number of counts in channel 147 was also recorded. Based on the previously stated assumptions, the Upper Edge should then be located at channel 204. The number of counts for this channel was recorded. Based on these values, it was determined that the Upper Edge was located at approximately 28\% of the height of that of the Compton Maximum. The counts in the Compton Maximum channel for the gains discussed in the previous section were recorded. Based on the assumption that the Upper Edge is at approximately $28 \%$ of the Compton Maximum, the count rates and thus corresponding channel numbers were determined. The results are given in Table 8.

Table 8. Calculated position of the Upper Edge

\begin{tabular}{|c|c|c|c|c|c|c|}
\hline $\begin{array}{c}\text { Channel } \\
\text { of } \\
\text { Compton } \\
\text { Maximum }\end{array}$ & $\begin{array}{c}\text { Counts in } \\
\text { Compton } \\
\text { Maximum } \\
\text { channel }\end{array}$ & $\begin{array}{c}\text { Expected } \\
\text { counts in } \\
\text { Upper Edge } \\
\text { channel }\end{array}$ & $\begin{array}{c}\text { Determined } \\
\text { Upper } \\
\text { Edge } \\
\text { channel }\end{array}$ & keV/ch & $\begin{array}{c}\text { LLD } \\
\text { channel } \\
\text { number }\end{array}$ & $\begin{array}{c}\text { ULD } \\
\text { channel } \\
\text { number }\end{array}$ \\
\hline $\mathbf{1 1 6}$ & 137100 & 38055 & 162 & 2.962963 & 6 & 36 \\
\hline $\mathbf{1 2 4}$ & 126669 & 35160 & 174 & 2.758621 & 7 & 39 \\
\hline $\mathbf{1 4 7}$ & 109759 & 30466 & 204 & 2.352941 & 8 & 46 \\
\hline $\mathbf{1 9 9}$ & 79111 & 21959 & 281 & 1.708185 & 10 & 64 \\
\hline $\mathbf{2 5 3}$ & 64506 & 17905 & 349 & 1.375358 & 13 & 79 \\
\hline $\mathbf{2 7 8}$ & 57863 & 16061 & 389 & 1.233933 & 14 & 88 \\
\hline $\mathbf{3 2 7}$ & 51455 & 14282 & LOST & NA & NA & NA \\
\hline $\mathbf{3 4 4}$ & 49599 & 13767 & LOST & NA & NA & NA \\
\hline $\mathbf{3 5 6}$ & 49377 & 13706 & LOST & NA & NA & NA \\
\hline $\mathbf{3 7 6}$ & 46330 & 12860 & LOST & NA & NA & NA \\
\hline
\end{tabular}

For a number of the measurements where the gains were very high, the Compton Maximum was pushed too far and the high-energy tail was buried in noise; The Upper Edge channel could not be determined.

If the Upper Edge is assumed to be close to the Compton Edge, we can assume the energy of the edge is approximately $480 \mathrm{keV}$. Based on the original alignment, where the Compton Maximum was at channel 147 and the Upper Edge is at channel 204, it follows that there are $2.3 \mathrm{keV}$ per channel. Using this value, the approximate energies of the LLD and the ULD were determined to be $16.6 \mathrm{keV}$ and $109.6 \mathrm{keV}$. Using the determined Upper Edge channel number, and again assuming an edge energy of $480 \mathrm{keV}$, the number of $\mathrm{keV}$ per channel was calculated for each gain scenario. This was then extended to determine the appropriate position of the LLD and the ULD. These calculated values are also shown in Table 8.

These newly determined discriminators were then applied as done in the previous section of this report. Figure 6 shows the figure of merit plot for the newly adjusted discriminators. 


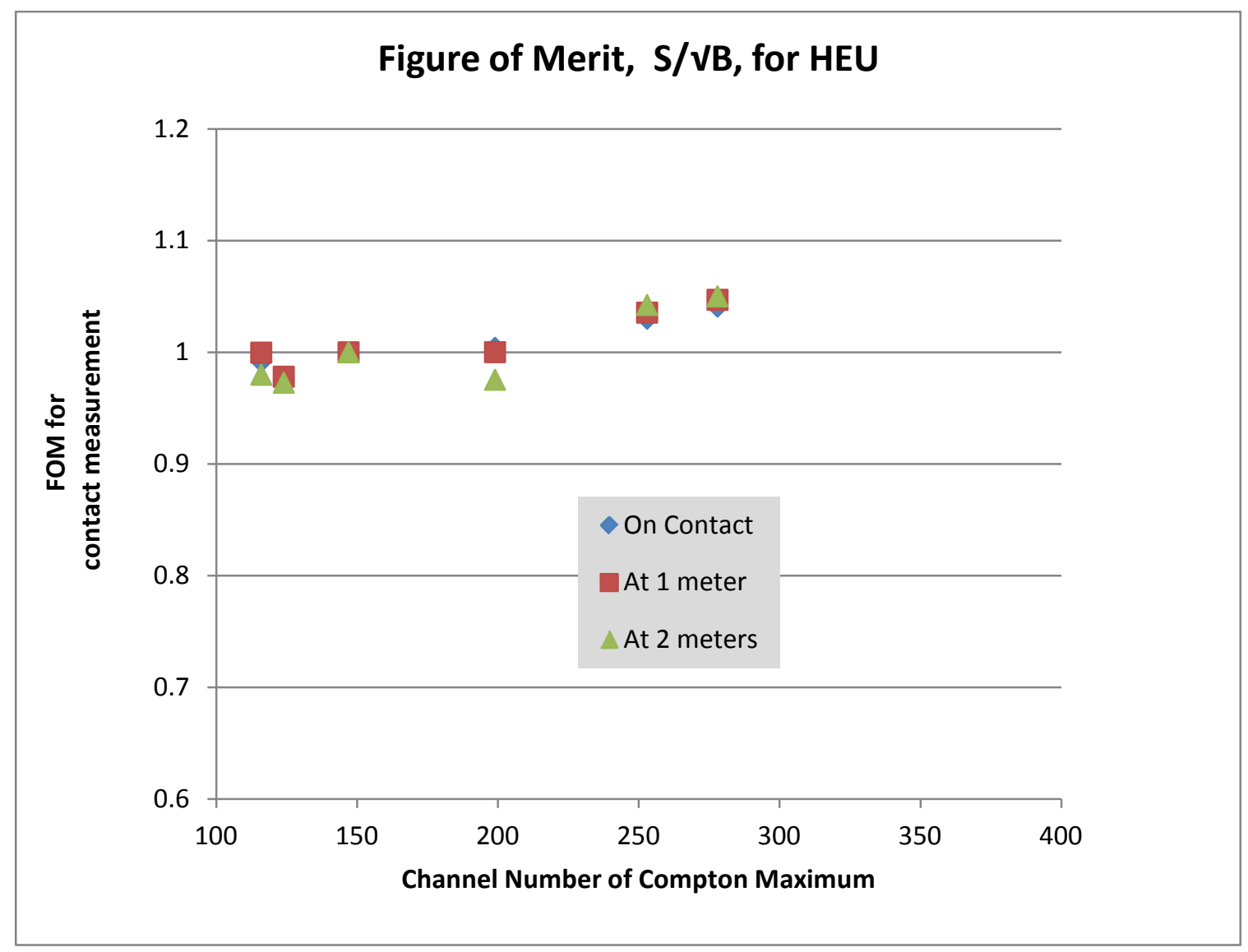

Figure 6. Normalized figure of merit for HEU measurements with adjusted discriminators.

Again, new discriminators for the high gain scenarios could not be determined. The figure of merit (with adjusted discriminators) plot shows a flatter profile for all source to detector distances in comparison to the figure of merit (with fixed discriminators) plot in Fig. 4.

Although Fig. 4 implies that additional sensitivity could be achieved with a higher gain setting, Fig. 6 shows that those potential gains are effectively erased when one considers appropriately adjusting the discriminators. ORNL does not consider the 4-5\% gain in sensitivity shown in Fig. 6 to be worth the administrative cost of changing program settings.

Additionally, the figure of merit was computed as a function of ULD position. Figure 7 shows the figure of merit as the ULD was increased. Currently, the ULD is set at approximately channel 46. 


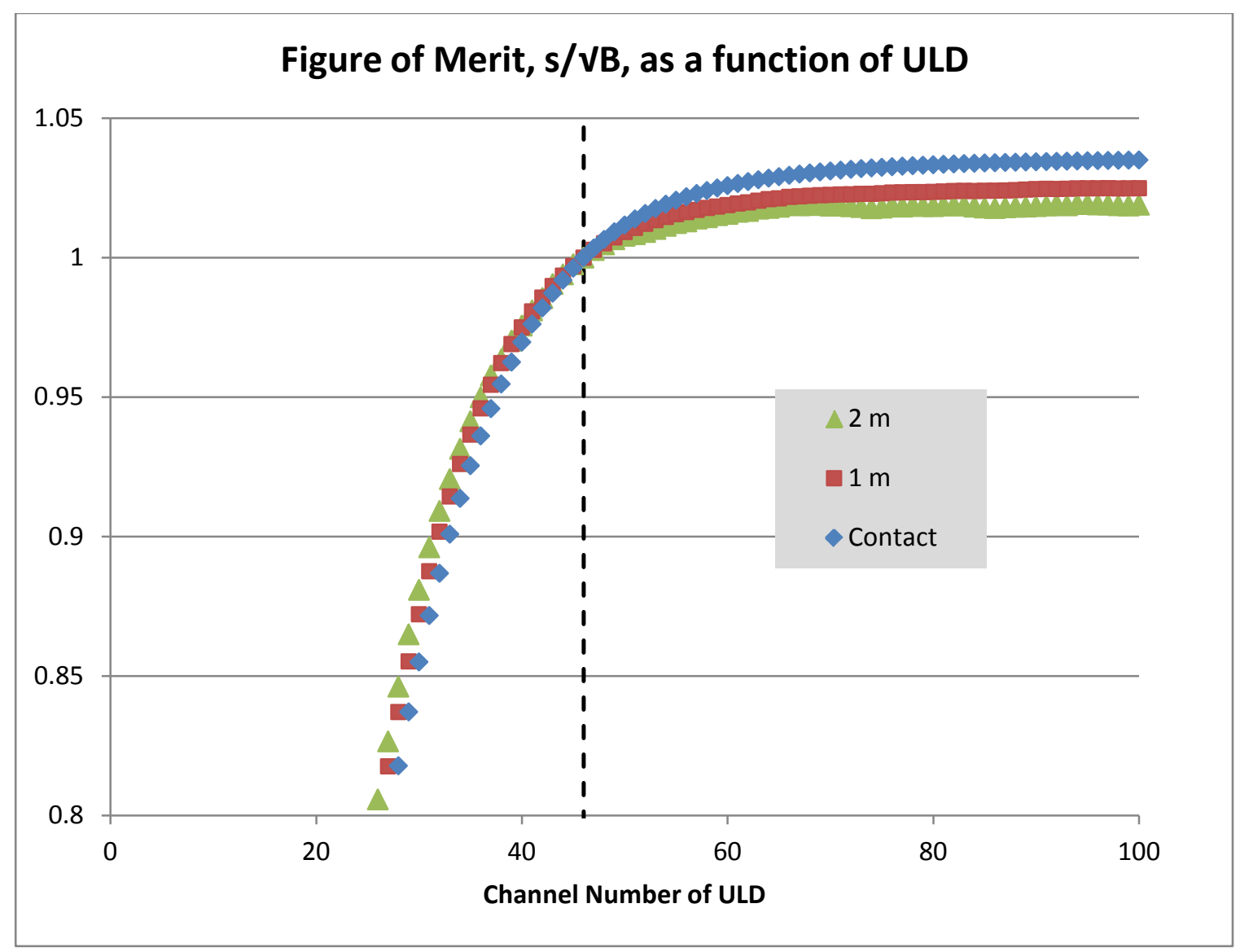

Fig. 7. Figure of merit as a function of ULD.

\section{CONCLUSIONS}

A number of conclusions can be drawn from the ORNL testing. First, for increased distance between the source and the detector, thus illuminating the entire detector rather than just the center of the detector (as is done during detector alignments), an increase in gain may provide a 5-15\% increase in sensitivity (Fig. 4). However, increasing the gain without adjusting the discriminator settings is not recommended as this makes the monitor more sensitive to electronic noise and temperature-induced fluctuations. Furthermore, if the discriminators are adjusted in relation to the increase in gain, thus appropriately discriminating against electronic noise, the sensitivity gains are less than 5\% (Fig. 6). ORNL does not consider this slight increase in sensitivity to be a worthwhile pursuit.

Second, increasing the ULD will increase sensitivity a few percent (Fig. 7); however, it is not clear that the slight increase in sensitivity is worth the effort required to make the change (e.g., 
reliability, cost, etc.). Additionally, while the monitor would be more sensitive to HEU, it would also be more sensitive to NORM.

Third, the sensitivity of the system remains approximately the same whether it is calibrated to a small source on contact or a large source far away (Fig. 6). This affirms that no changes to the existing calibration procedure are necessary.

\section{REFERENCES}

H. Volz, C. Lovejoy, A. Lousteau, and J. Livesay, Multichannel Analyzer Alignment

Procedure for TSA Radiation Portal Monitors, LA-CP-12-00095, Los Alamos National Laboratory (2012). 